\section{FACTORS ASSOCIATED WITH OCCUPATIONAL SOCIALIZATION IN RURAL NEPAL}

Kiran Dutta Upadhyay

A country's future development is shouldered by the youth, especially in Nepal, where the majority of the populace is young and lives in rural areas. However, rural youth are not being provided with the opportunity to realize their potential. Youth is a transitional period in the personality development process and bridges the stages of childhood and adulthood; it is the period when individuals shape their future careers. Because 1985 was declared "International Youth Year", Nepal should examine the plight of its rural youth, their occupational aspirations and expectations.

First and foremost, this paper aims to operationalize the term occupational socialization. In this study, occupational socialization embraces both occupational aspirations and expectations. Socialization is the process by which the individual learns to conform to the norms of his social group, acquires a status, plays a corresponding role, and emerges with a personality.

Occupational aspiration pertains to the kind or type of work the youth wants to have, whereas occupational expectation refers to the kind or type of work the youth expects to have in regards to economic resources and other opportunities. Occupational aspiration and expectation were categorized as "blue-collar job" or "white-collar job" based on the nature of the work. The youth who hoped for skilled jobs, professional work, labour on and off the farm were categorized under "blue-collar job." Those who would desire and expect official jobs were categorised under "white-collar job."

In Nepalese society, the occupation of the parents has a great influence on the children. The parents' influence on children was also observed in the developed society. In the regard, Nelson (1960:313) opined that American children whose parents were teachers, journalists and physicians tended to select their fathers' occupations. This indicates that educated parents had a strong influence over the occupational direction of their children.

In the occupational socialization process, education plays a vital role since it may serve as a passport for an individual to move towards the upper stratum of social stratification. If an individual is able to acquire more education, there is a greater probability that he will be able to obtain a white collar job. But the majority of Nepali rural youths lack education and as a result they are compelled to remain in "blue-collar jobs." This may be due to the poor economic condition of their parents.

In this regard, Cabriles' study (1978:43) showed that in the Philippines a financial problem was the major reason for dropping out of school. Other factors, listed in order of frequency, were lack of interest, poor health, changing residences and getting married.

Gasson (1968:317-326) has stressed that there is a strong tendency for the sons of farmers to work in jobs related to agriculture. The following paragraph tries to analyze the proportion of the youth on the basis of two population censuses, 1971 and 1981 respectively.

Table 1 presents Nepal's population by 5 year age groups. From Table 1, it may be inferred that the majority of the population is in the age group under 24 years. This study is concerned only with the responses from people whose age ranged from 10 to 25 years. In other words, the presentation is concerned only with the age categories $10-14$ years, $15-19$ years and 20-24 years. According to the 1971 census, these groups constitute $11.2,9.1$ and 8.4 per cent, respectively, of the total population of Nepal, which comes to 28.7 per cent. Similarly, according to the 1981 census these groups constitute $11.4,8.8$ and 8.9 per cent respectively, which comes to 29.1 percent. In both cases, the youths occupy more than one-forth of the total population of the country, and the number in these groups has increased. An individual's career begins sometime during this period. Hence, a wise look in these age groups is crucial for policy makers. If these youths do not get adequate opportunities to become better educated and better skilled, they remain unproductive, unemployed, or under-employed, and forced to remain only in blue-collar jobs. 
Table - 1: Population of Nepal by Age Group According to Population Census of 1971 and 1981

\begin{tabular}{|r|r|r|r|r|}
\hline \multirow{2}{*}{ Age Group } & \multicolumn{2}{|c|}{ Census of 1971 } & \multicolumn{2}{c|}{ Census of 1981 } \\
\cline { 2 - 5 } & \multicolumn{1}{c|}{ Number } & Percent & Number & Percent \\
\hline Under 5 years & $1,634,110$ & 14.1 & $2,314,505$ & 15.4 \\
5-9 years & $1,743,253$ & 15.1 & $2,190,446$ & 14.6 \\
10-14 years & $1,297,215$ & 11.2 & $1,707,021$ & 11.4 \\
15-19 years & $1,047,459$ & 9.1 & $1,328,401$ & 8.8 \\
20-24 years & 969,675 & 8.4 & $1,335,098$ & 8.9 \\
25-29 years & 930,287 & 8.1 & $1,161,670$ & 7.7 \\
30-34 years & 811,401 & 7.0 & 975,401 & 6.5 \\
35-39 years & 744,788 & 6.4 & 884,572 & 5.9 \\
40-44 years & 609,461 & 5.3 & 752,788 & 5.0 \\
45-49 years & 461,098 & 4.0 & 618,805 & 4.1 \\
50-54 years & 400,834 & 3.5 & 531,322 & 3.6 \\
55-59 years & 257,699 & 2.2 & 365,749 & 2.4 \\
60-64 years & 294,230 & 2.5 & 367,495 & 2.5 \\
65-69 years & $354,473 *$ & 3.1 & 188,583 & 1.3 \\
$70-74$ years & - & - & 156,786 & 1.0 \\
$75-79$ years & - & - & 66,393 & 0.4 \\
80-84 years & - & - & 50,231 & 0.3 \\
85 years and above & - & - & 27,573 & 0.2 \\
\hline Total & $11,555,983$ & 100.0 & $15,022,839$ & 100.0 \\
\hline
\end{tabular}

*65 years and above

Ginzberg perceived a person's development process in three stages, namely: (a) fantasy choice, the latency period (six to eleven); (b) tentative choice, adolescence; and (c) realistic choice, late teens to early twenties. Super (Ohlson 1964:337) reinforced Ginzberg's point when he said that the "maturation of an individual's abilities, interest and aptitude, his opportunity for testing, and his self-concept influence his career development." It is the nation's responsibility to provide youth opportunities to make them productive citizens.

The rural areas have in-school, out-of-school and noschooling youths who experience different degrees of the socialization process guiding them in their development. They look at themselves in different ways. It is a fact that rural youths of developing countries are reminded daily that the best road leads to town. They consider imported commodities to be symbols of high status. The emergence and enthusiasm of this vast potential youth population, if employed in profitable ways, can make Nepal much more prosperous than it now is. Considering these basic truths, it has become a challenging job for planners and policy makers to channel the energy of these rural youths for the country's future development. Keeping this view in mind, this study aims to examine the occupational socialization process of rural youths.

\section{Place and Population of the Study}

This study was conducted in Rautahat District of Nepal, which lies on the South-Central belt of the country in the Central Development Region in Narayani Zone. There were 52 village panchayats in the district with approximately 57,300 farm households. Only nine panchayats had high schools, and of those, three were randomly selected: Santapur, Pipra Bhalohiya and Potihahi Dharahari. From the three different sample village panchayats, a proportionate sample of 122 youths (10 per cent) was drawn randomly.

\section{Hypothesis of the Study}

The null hypothesis was that the youth's preference for an occupation is not associated with their demographic-socioeconomic characteristics or with their family background.

\section{Method of Analysis}

The data was classified and analyzed in terms of their statistical meaning and significance taking into consideration the objective. The Chi-square test(X2) was computed. The hypothesis was accepted or rejected at 0.05 level of significance, presented in Table 2.

\section{Presentation}

The chi-square independence revealed that marital status of youths was significantly related to occupational socialization. It showed that the majority of those who were married, as 
compared to those who were single, aspired for and expected blue-collar jobs. It is safe to presume that the single youths, having less responsibilities in the family, had more possibility of achieving higher education and that they have more mobility than the married youths, and thus they had more knowledge about jobs. These may be some of the reasons why they could aspire to and expect to get more white-collar jobs. Married youths had greater responsibilities to their families and remain engaged in either farming or labour in the village.

The position of siblings in a family was found highly associated with the youth's occupational socialization. The majority of the eldest did not aspire for white-collar jobs as compared to their middle and younger relatives.

The chi-square test revealed that caste of the youth was highly related to occupational aspiration and expectation (Occupational socialization). It is safe to presume that the youths who belonged to the higher castes had greater exposure to alternative occupations, and therefore aspired for white-collar jobs.

Statistically, those who had at least middle and high school education aspired for white-collar jobs. Here the relationship was direct and positive. The youths who had high and middle school educations could expect white-collar jobs because of their exposure to education and employment opportunities.

The chi-square results also revealed that the tenure status and size of farm land of parents significantly affected occupational socialization. Children of owner-cultivators with large land holdings could expect white-collar jobs more than youths whose parents were tenants and had small land holdings. It was obvious that land-owning parents wished to give their children as much education as they could afford. This was made possible because of an adequate annual income. As a result of the better educational possibilities, their children could aspire for white-collar jobs.

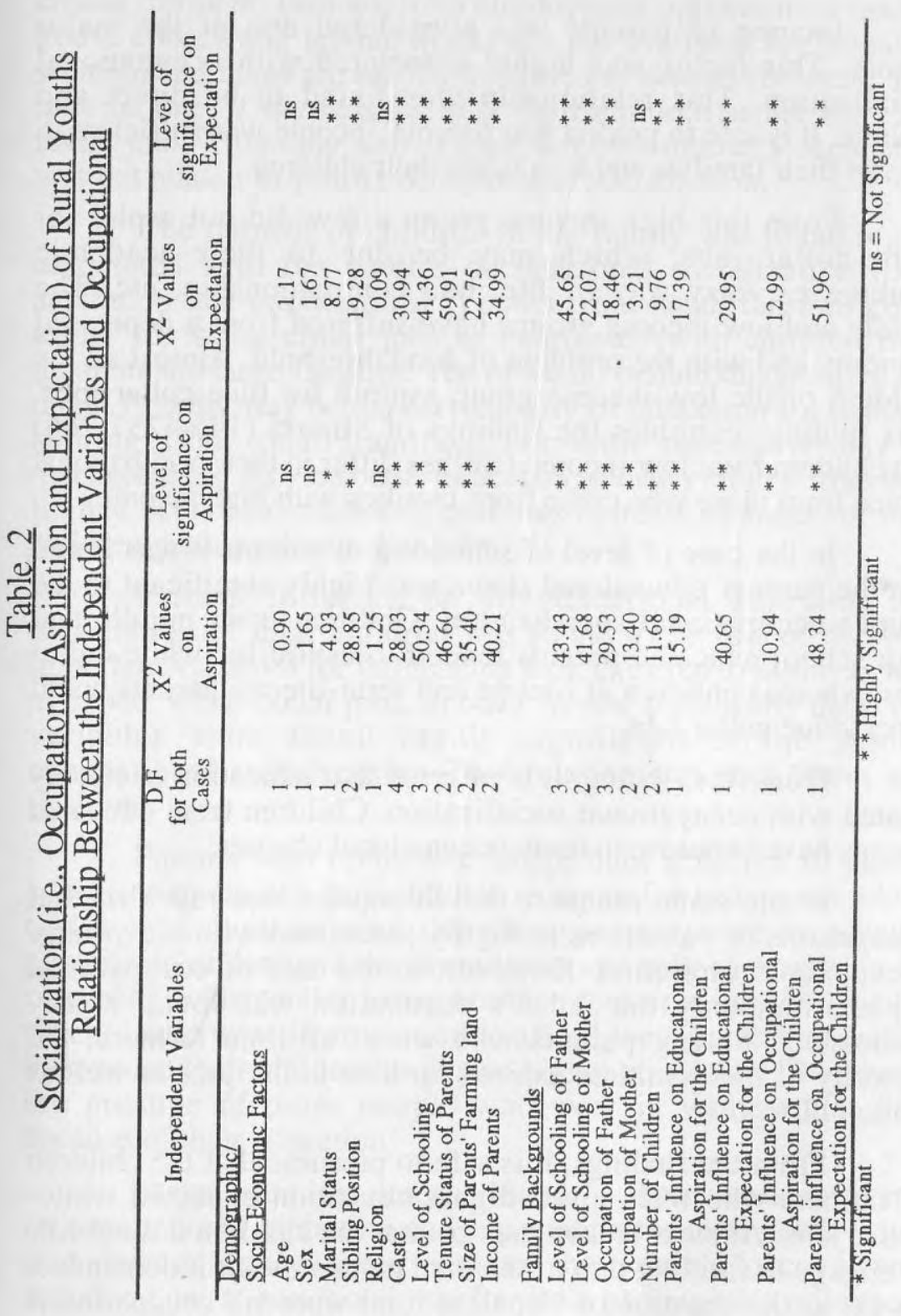


Income of parents was considered one of the major factors. This factor was highly associated with occupational socialization. This relationship was found to be direct and positive. It is safe to predict that parents' income was sufficient to support their families and to educate their children.

From this high income group a few did not aspire for white-collar jobs, which may be due to their academic weaknesses, easy way of life, bad companionship, etc. The middle and low income groups have suffered from a depressed economy and with the problem of food threshold. Almost all the children of the low-income group aspired for blue-collar jobs. This finding resembles the findings of Strauss (1964:257-266) that children from low-income families differ in their occupational choice from those who come from families with high income.

In the case of level of schooling of parents it was found that the parents' educational status was highly significant to the youth's occupational socialization. Children from middle and high school educated parents tended to aspire for white-collar jobs, whereas children of literate and semi-literate parents could expect blue-collar jobs.

From this finding, it is inferred that education is closely related with occupational socialization. Children from educated parents have exposure to more occupational choices.

In the same manner, the chi-square test revealed that occupations of parents were highly associated with the youths' occupational aspiration. However, in the case of occupational expectation, only the father's occupation was found highly associated. Among parents who were full-time farmers, the majority of their children aspired for blue-collar jobs as well as white-collar jobs.

From the findings, it is safe to presume that the children of farmers who were given higher education expected whitecollar jobs. Another reason may be that the children did not like to engage in farming due to the hard manual work it demanded. As far as the question of Nepalese rural women's occupation is concerned, women from the well-to-do families do not work outside because of their social status and also because it is not crucial for them. Besides, rural employment opportunities (except house chores and labour work) are not available for Nepalese women, and these are neither suitable nor crucial for them. This may be one of the reasons why their children aspire for bluecollar jobs. This may also explain why the mother's occupation was not related to youth's occupational socialization.

The number of children in the family was found highly associated with the youth's occupational socialization (both aspiration and expectation). Youths from small families could aspire for white-collar jobs as contralsted with children from medium and large families. The rationale behind this positive and direct finding may be the accessibility of education for children coming from small families. For their parents it may be manageable to provide better education to their children from their limited economic resources, and thus increase chances for their children getting white-collar jobs.

Parents' influence on the educational aspiration and expectation of their children was found to be one of the very important variables for influencing their children to aspire as well as expect white-collar jobs. In other words, statistically these two variables were found highly significant to the youths' occupational socialization. This relationship was direct and positive.

Parents who could encourage their children to pursue education motivated their children to aspire for and expect whitecollar jobs. It is inferred that their parents were in a better position to understand the importance and role: of education for obtaining white-collar jobs. Another reason nnight be that the parents who were in a position to afford their youth's education influenced their children to pursue higher education. They knew the prestige of those people who were in white-collar jobs because: of their education.

In the same line, another factor -- the parents' influence on occupational aspiration and expectation for their youth -- was also found highly significant to the youth's occupational socialization. It was found that for those parents who influenced their children for blue-collar jobs, the majority of children likewise aspired for and expected blue-collar jobs. Similarly, if 
the parents could influence their children for white-collar jobs, the children could aspire for and expect white-collar jobs.

The rationale behind such behavior is obvious. Because the parents were in a blue-collar job, their children were exposed to such work, and similarly with the children whose parents were in a white-collar job. This confirms the findings of Melecio (1976) that there exists a strong relationship between the youths' perceiving the parents' occupational aspirations for them and their occupational choices.

The youth's occupational socialization processes (aspirations and expectations) were influenced by almost all the independent variables which have been taken into consideration in this study except their age, sex, religion, and occupation of the mother. The above findings reject the null hypothesis that the occupational socialization of the rural youths were not associated with their demographic-socio-economic factors and family backgrounds. Hence, there is a crucial need to prepare a constructive plan to provide opportunities of socio-educational services which could tap the potentialities of youths, a great majority of whom are in rural areas. Of course, it is a challenging job for policy-makers, planners and other authorities in this field.

Policy Recommendations: Before implementing any rural youth programme, certain points need to be considered and determined: what needs to be done, where to begin, and how to divide responsibilities. The new programme must begin on a small scale and expand with an increase in trained personnel. What people at the local level want may be entirely different from what national policy-makers think they need. The felt needs of rural youths can be the most important consideration and the best starting point in determining the direction and content of a rural youth programme. Programmes based on village needs will create cooperation and enthusiasm with villagers in working for their upliftment.

It is crucial to tap the youths' potentialities by providing them with education and other opportunities, so that they may be in a position to change their socio-educational and economic environment. It is a fact that education serves as a passport for ascending to a higher stratum and for the social mobility of an individual.

In the Nepalese context, the majority of rural youths are either non-schooling or out-of-schooling. Because they are of school-going age, efforts should be made to get them back to school; and if that is not possible, then it is crucial to devise special vocational programmes for them. In this regard, it will be good to impart skills for employment and income generating activities such as woodworking, masonry, plumbing, and other farm related training. The development of the country is possible only when the youth's developed skills can be utilized. 


\section{REFERENCES}

Cabriles, David C.

1978 "Youth Resources Mobilization: A Development Strategy in Maramag." Unpublished M.S. Thesis. Bukidnon: UPLB College, Laguana.

Coombs, et. al.

1972 New Path to Learning for Children and Youth. New York: International Council for Educational Development.

Gasson, Ruth.

1968 "Occupations Chosen by Sons of Farmers." Journal of Agricultural Economics, Vol. 19, No. 3.

His Majesty's Government of Nepal.

1975a Population Census 1971. Central Bureau of Statistics: Imperial Calendar, Co. Pvt., Calcutta - 13.

1975b Population Census - 1981, Table 5.

Melecio, Esteban E.

1976 "Occupational Aspiration of Students in the Two-Year Agricultural Technician Curriculum." Unpublished M.S. Thesis, UPLB, College, Laguna.

Nelson, et. al.

1960 Communication Structure and Change. New York: The McMillan Press and Co.

Ohlson, Merle.

1964 Guidance Services in the Modern School. Javanovich, New York: Harcourt and Brace.

Strauss, Murray A.

1964 "Personal Needs and Functional Characteristics in the Choice of Farming and Occupations." Rural Sociology, Vol. 4.

\section{DEVELOPMENT AND UNDERDEVELOPMENT:}

A PRELIMINARY SOCIOLOGICAL PERSPECTIVE1

Chaitanya Mishra

\section{Introduction}

The notion of development, despite its universal currency and exhortatory potential, in some ways reminds one of the story of the elephant and the six blind men. "Development" is somehow holy, uplifting and attractive. It is, however, also mysterious. The object is subjectively perceived and the totality of subjectivities does not add up to an objective description and/or assessment. Instead the totality becomes more and more grotesque, unfamiliar and abstract. A goal which is itself mysterious, in turn, inspires a mode of practice which is essentially misleading.

On the other hand, a valid conceptualization of the "developmental problem," would enable us to a) shed the mystery embedded in the notions of development and underdevelopment; b) assess current developmental practice more objectively; and c) sift alternative potential bases for development. Put another way, a valid conceptualization of the "developmental problem" would help us enumerate and analyze constraints against and options for what might be an adequate design for future development.

It is one of the more general central arguments of this paper that a valid conceptualization of the "development problem" can be approximated by analyzing a set of three structural processes: those related to the capitalistic world-system -- the capitalistic world-economy in particular, the internal class relationships within a given sub-world economy, and the form of utilization of political-economic resource. It should be emphasized that these parameters are distinct only analytically; these are parts of a historical process, united within a historical whole. These parameters can be made more specific and their mutual relationships unraveled only as part of an effort geared at 